OPEN ACCESS

\title{
University of Dundee
}

\section{Introduction to Birth's special issue}

McFadden, Alison; MacDorman, Marian

Published in:

Birth

DOI:

10.1111/birt.12447

Publication date:

2019

\section{Document Version}

Peer reviewed version

Link to publication in Discovery Research Portal

Citation for published version (APA):

McFadden, A., \& MacDorman, M. (2019). Introduction to Birth's special issue: Quality of care II. Birth, 46(3), 389-390. https://doi.org/10.1111/birt.12447

\section{General rights}

Copyright and moral rights for the publications made accessible in Discovery Research Portal are retained by the authors and/or other copyright owners and it is a condition of accessing publications that users recognise and abide by the legal requirements associated with these rights.

- Users may download and print one copy of any publication from Discovery Research Portal for the purpose of private study or research.

- You may not further distribute the material or use it for any profit-making activity or commercial gain.

- You may freely distribute the URL identifying the publication in the public portal.

Take down policy

If you believe that this document breaches copyright please contact us providing details, and we will remove access to the work immediately and investigate your claim. 


\section{McFadden, Alison and Marian MacDorman. "Introduction to Birth's special issue: Quality of care II". Birth. 2019, 46(3). 389-390. https://doi.org/10.1111/birt.12447 \\ Introduction to Birth's Special Issue: Quality of Care II}

Welcome to Birth's second special issue on quality of care. In 2018, Kennedy et al published a call to action for research to improve the quality of care for every woman and every child (1). This call to action was informed by a research prioritisation process based on the critical knowledge gaps identified from the 2014 Lancet Series on Midwifery (2). The results identified the need for 'right care' defined as 'quality care that is tailored to individuals, weighs benefits and harms, is person-centred, works across the whole continuum of care, advances equity, and is informed by evidence, including cost-effectiveness'. Three priority inter-related research themes were identified:

A. Evaluate the effectiveness of midwifery care as defined by the Quality Maternal and Newborn Care framework (3) and the contribution of its components, when compared to other models of care across various settings, particularly on rates of maternal/fetal/infant death, preterm birth, and low birth weight; and on access to and acceptability of family planning services.

B. Identify and describe aspects of care that optimize, and those that disturb, the biological/physiological processes for healthy childbearing women and fetus/newborn infants and for those who experience complications.

C. Determine which indicators, measures, and benchmarks are most valuable in assessing quality maternal and newborn care across settings, including the views of women; and develop new ones to address identified gaps.

This collection of papers addresses the first two of the above priorities highlighting women's experiences of care, evaluations of the provision of midwifery care and strategies for minimising intervention and promoting normal processes.

Women's experiences of their care is an important marker of quality care. Allen and colleagues report from a randomised controlled trial that women allocated to caseload midwifery perceived a higher level of quality of care than those receiving standard care, while Rijnders and colleagues found that women who received group antenatal care felt more supported to participate actively in their care and were better able to voice their opinions than those receiving individual care. Less positive experiences were 
found by Lou and colleagues related to women's experiences of postterm induction of labour where women did not feel involved in decision-making, and were expected to fit into hospital routines. In terms of tailoring care to individual circumstances, Rayment-Jones and colleagues focussed on experiences of UK maternity care of women with social risk factors in their realist synthesis. The findings highlight the importance of early access, meaningful engagement and reducing fear and discrimination to developing safe, person-centred maternity services.

Reducing the iatrogenic risk of overtreatment is identified by Kennedy et al as a particular risk in high resource settings. A team of researchers examined the influence of midwifery in integrated, team-based models of care in the USA finding that nulliparous women (Neal and colleagues) and parous women (Carlson and colleagues) have lower intervention rates compared to non-interprofessional centers. Altaweli and colleagues identified routine use of interventions in Saudi Arabia influenced by the organisational culture, medical dominance, and a hierarchical system of control. In contrast, Surita and Giordano describe the impact of a respectful maternity care support group in reducing caesarean rates for participant women, even in the context of a high caesarean rate country such as Brazil.

Evidence-informed care is a core tenet of high quality care, however, the challenges of implementing evidence into practice are well-established. Anton and colleagues highlight strategies to implement placental transfusion at birth while MacVicar and Kelly highlight facilitators and barriers to nonpharmacological management of neonatal abstinence syndrome. Rubashkin and colleagues illuminate how practitioners may justify using interventions that they know are not evidence-based. The participants in their qualitative study not only persisted in using uterine fundal pressure but made it difficult for women to refuse the intervention.

Two papers from very different settings examine the potential of education to optimise the capability of healthcare workers to provide high quality care. Afulani and colleagues found that incorporating reflection on respectful maternity care in the context of emergency obstetric simulations can improve women's experiences of maternity care in Ghana, while in the UK, Coates and colleagues report that a postgraduate midwifery module increased participants' skills, knowledge and confidence related to supporting physiological birth, empowerment and avoiding unnecessary intervention.

We hope you find this collection of papers interesting and relevant. Happy reading!

\section{Alison McFadden and Marian MacDorman, special issue co-editors}




\section{References}

1. Kennedy HP, Cheyney M, Dahlen HG et al. Asking different questions: A call to action for research to improve the quality of care for every woman, every child. Birth 2018;45(3):222-31.

2. Horton R, Astudillo O. The power of midwifery. Lancet 2014;384(9948):1075-6.

3. Renfrew MJ, McFadden A, Bastos MH et al. Midwifery and quality care: findings from a new evidence-informed framework for maternal and newborn care. Lancet 2014;384:1146-57. 